\title{
Agriculture Innovation, Organic Farming and Gene Editing: The Way Forward
}

Valeria Sodano*

Department of Political Science University Federico II of Naples Via Rodinò 22, Napoli, Italy
ISSN: 2637-7659

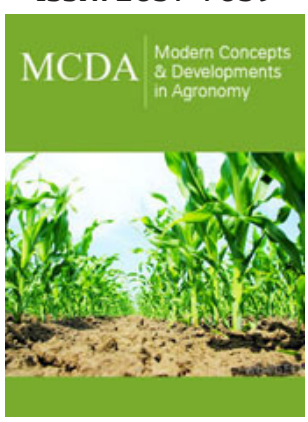

*Corresponding author: Valeria Sodano, Department of Political Science University Federico II of Naples Via Rodinò 22, Napoli, Italy

Submission: 泟 January 12, 2021

Published: 制January 27, 2021

Volume 7 - Issue 5

How to cite this article: Valeria Sodano. Agriculture Innovation, Organic Farming and Gene Editing: The Way Forward. Mod Concep Dev Agrono. 7(5). MCDA. 000675. 2021. DOI: 10.31031/MCDA.2021.07.000675

Copyright@ Valeria Sodano, This article is distributed under the terms of the Creative Commons Attribution 4.0 International License, which permits unrestricted use and redistribution provided that the original author and source are credited.

\begin{abstract}
The article provides an account of the recent debate on the use of new gene editing technologies in the organic farming sector. After a brief reference to the possible uses of these technologies in the agri-food sector and the existing regulations, the positions taken by organic agriculture are summarized. So far, a cautious precautionary principle has been embraced which has led the organic sector to refuse gene editing on the basis of the two following arguments: 1. the technology does still not prove to be beneficial to society and be able to promote sustainable development; 2. there are too many areas of incertitude with respect to its possible adverse effects at environmental and social justice level. Gene technologies have also been rejected because of their incompatibility with the four founding principles of organic agriculture: health, ecology, fairness, and care. Notwithstanding the sharp current position, the debate is still open, with many social and economic forces which, potentially, might lead to different scenarios.
\end{abstract}

Keywords: Gene editing;Organic;Agriculture;Regulation;Sustainability

\section{Introduction}

In recent years, and especially after the seminal work on the CRISPR-Cas system by Doudna [1], the new genome editing techniques have been hailed as the new frontier of biotechnological research capable of bringing enormous benefits in the medical, environmental and agricultural fields.

This brief note intends to make a very limited contribution on a particular aspect of the debate on the new biotechnologies in agriculture, namely the opening or not of organic farming to such technologies. The aim of the work is not to provide an exhaustive account of the ongoing debate, which would in any case be impossible in the limited space available, but to focus attention on some aspects of the issue that seem to be particularly relevant for taking a clear position on how to regulate the new technologies in organic farming.

Our commentary develops by presenting the following three topics: the promises and risks of gene editing and regulatory models; the position of organic farmers' associations; the identification of some real data and key principles useful to draw regulatory guidelines for biotechnological innovation in the organic sector.

\section{Gene editing: applications, risks and regulation}

The early genome editing systems involved ODM (oligonucleotide-directed mutagenesis) TALENs (transcription activator-like effector nucleases) and ZFNs (zinc finger nucleases). These technologies gave raise to limited applications because of their transfection inefficiency and design complexity. Currently, the dominant genome editing is the CRISPR-Cas (clustered regularly interspaced short palindromic repeats and CRISPR associated proteins) due to its efficiency, precision and wide application range. While biomedical and clinical applications seem to be very promising yet still in their infancy, with many safety issues still to be clarified, applications in the agriculture are rapidly growing, with far less safety concerns [2]. The main advantage of CRISPR technology is the possibility of dramatically reducing time in animal and crop breeding programs till a as few as 2-3 years. As a consequence, the introduction of many new traits and functions can be easily experimented and quickly released on the market, with lower financial risks for the companies involved in the innovation programs.

So far, many applications have been featured, with some already in an advanced stage of experimentation, but only a few already on the market. With respect to crops five areas of innovation are being explored [3]: 
1. Biotic stress resistance (for example CRISPR system has been used to make cassava resistant to brown streak disease and mosaic virus, spinach resistant to fire blight, maize resistant to lethal necrosis, grapevine resistant to powdery mildew, and so on).

2. Resistance to abiotic stress, such as drought, salinity and extreme temperatures.

3. Increased nutritional traits, such as potatoes with lower acrylamide or wheat with a lower gliadin content.

4. Higher yields.

5. Fitness to the increasing industrialization of the food chain (longer shelf-life, delayed ripening, modified enzymatic activity, aesthetic changes and product uniformity).

In animals' genome editing has been used in fish, pig, sheep, cattle, and chicken to increase disease resistance, to improve fertility and foster muscle development and body growth. Most applications [4] involve higher productivity and modified traits that make animals more resistant to the biotic and abiotic stress associated with the unhealthy environment of intensive animal farming (such as hornlessness and resistance to bacteria and fungi present in overcrowded stables).

Despite the seemingly simplicity and precision of gene editing techniques, there are still some concerns about their application on a large scale in agriculture, including the most recent CRISPR-Cas system. The biggest concern is the possibility of deleterious effects caused by the integration of transgenic constructs or off-target mutations. The off-target effects of the CRISPR-Cas system in plants have been reported by many studies [5] and, although innovative procedures are being developed in order to avoid them, there is still great uncertainty and lack of knowledge about the issue [6]. Unpredictable effects of existing genome-editing systems depend on the fact that the desired genetical changes are obtained through the uncontrolled participation of endogenous DNA repair factors which are error-prone. As it has been recently pointed out, the range of possible molecular events resulting from genome editing has been underestimated and the technology remains unpredictable on, and away from, the target locus, with considerable impact on providing a safe approach for therapeutic genome editing, agriculture, and other applications [7]. Gene editing regulation has closely followed GMO regulation. Countries with a weak GMO regulation, such as Canada, the United States and Argentina have chosen an even softer attitude towards gene editing, excluding any form of regulation for plants produced by using genome editing techniques if they do not contain foreign DNA [8]. Countries with tougher GMO regulation, such as the European Union, have instead stated that organism produced through mutagenesis mechanisms which do not occur naturally should be subjected to the same GMO regulation [9].

Overall, there is scant consensus on the actual level of risk associated with the new gene edited organisms. There is also a limited literature on risk assessment, while there is generally agreement that this should be done on a case-by-case basis and considering both process and product associated risk. Risks associated with the genome editing processes include unintended changes of the genome, epigenome, transcriptome, metabolome and microbiome, while risks associated with the trait refer to possible unintended effects at the molecular, cellular, organismal and ecosystem levels [4].

Besides health and environmental risks, genome-edited organisms for food or feed may raise societal, ethical and environmental concerns, the so-called non-safety risks. While most countries do not require a non-safety assessment for approval of the gene edited organisms, there are some exceptions, such as the Norwegian Gene Technology Act, which requires that the sustainability, ethical and societal impacts of a genetically modified organism should be assessed prior to regulatory approval of the novel products [10]. The rationale beyond non-safety risk assessment is the safeguard of a productive sector which is meant to deliver products and services crucial for the fulfillment of a plethora of human rights. The capability of the food system to deliver safe and affordable food with production processes that can be easily and freely accessible to individuals and states is clearly a condition for democracy and state sovereignty as well as for the fundamental right to life, which is linked to the rights to food and health.

Genome editing technologies may be considered as disruptive technologies, since they can in a short time make alternative technologies obsolete and not any more accessible, with the worst case being the irremediable loss of traditional seeds and animals with their original genetic material intact and reproducible in nature. Anyway, the new gene technologies are embedded in patent systems which preclude fair and universal accessibility and exacerbate the disproportionate power imbalances already present in the global food supply chain. As a consequence, they pose economic, social and ethical risks which seem to be no less dangerous than safety risks. Like other radical technologies, such as nanotechnologies and digital technologies, the new breeding technologies are likely to support and reinforce the techno corporate agri-food paradigm [11] within the latest food regime [12]. They serve, interalia, to change people's understanding of food and nutrition, separating ever-further the consumption from the production sphere severing the bond between nature and food, and accustoming the consumer to the new diets and lifestyles imposed by corporate marketing policies [13].

\section{The position of organic farming associations on biotechnologies}

With respect to gene editing technology the organic sector so far has kept the same critical stances deployed with regard to "traditional" GMOs. So far, the organic sector has fiercely opposed genetically modified organisms (GMOs) continuing to offer guarantee to consumers that organic food does not contain GMOs 
(Organic Trade Association, 2020). In its latest papers on the issue, IFOAM-Organics International reaffirmed its position that "GMOs and their derivatives have no place in organic food and farming systems; in exceptional circumstances vaccines produced through genetic engineering are allowed in organic livestock, when no other alternatives are available or where their use is necessary to comply with legal requirements" [14]. IFOAM gives a clear definition of GMO, which is plant, animal, or microorganism that is transformed by genetic engineering (GE), where GE is referred to as "a set of techniques from molecular biology (such as recombinant DNA and RNA) by which the genetic material of plants, animals, microorganisms, cells and other biological units are altered in ways or with results that could not be obtained by methods of natural mating and reproduction or natural recombination".

GE includes genome editing systems like ODM, ZFNs TALENs, and CRISPRs, while does not include techniques such as conjugation, transduction, natural hybridization, and marker assisted breeding [14]. IFOAM briefly but very rigorously clarifies the reasons behind its position towards gene editing. While referring to the IFOAM report for a detailed explanation of the decisions made, here we recall the main criterion underlying these decisions, which is the compatibility of the new technologies with the four founding Principles of Organic Agriculture: Health, Ecology, Fairness, and Care. First, the irresponsible environmental release of GMOs has caused and continues to cause significant reduction in biodiversity, soil fertility, human and animal nutrition and health, therefore violating the Principle of Ecology and the Principle of Health. Second, the presence of GMOs and the policies that allow them to have resulted in reduction in farmers' choice about what they have opportunity to grow and reduction in consumers' choice regarding what foods they will provide to their families, violating the Principle of Fairness. Third, the Principle of Care, which requires that the potential for negative impacts on the environment and society be avoided with the utmost precaution and that those who develop and spread the technology be accountable for negative effects, has also been violated.

In conclusion, the final IFOAM position so far is that: "Products such as GMOs must not be introduced, unless they have been subjected to a rigorous, democratic, and transparent assessment of the technology through participatory processes that include decision-makers from every area of society and every group of people who will be impacted by the technology; any introduction of GMOs should be limited to controllable circumstances" [15].

Notwithstanding the clear position of IFOAM, there are some voices who call for a softer stance towards gene editing, agreeing with the use of the new breeding technologies when they bring concrete environmental benefits $[16,17]$. The lingering doubts and controversies on the possible use of the new breeding technologies in the organic sector depend on the powerful imaginary that the proponents of gene editing have built and spread. Such an imaginary rests on three arguments [18]: gene editing is not GMO; gene editing can deliver a new green revolution; gene editing can democratize agricultural biotechnologies. In order to add solid reasons for the refusal of gene editing by organic farming, a choice already well motivated by the inconsistency with the organic farming principles, it is useful to examine the three arguments in favor of gene editing and asses their actual veracity.

The statement that gene edited organism are not GMOs contradicts the latest warnings scientists gave in the light of the many unknown effects of the new breeding technologies. The response of the whole genome of organism to localized DNA deletions and induced mutations is unpredictable. Also, the argument that this was what has always been happening with old breeding techniques based on mutations induced via radiations or chemicals is not reassuring; this is because the new techniques are much more effective in inducing mutations while preserving for more reproductive cycles the organism integrity, meaning that adverse effects may show off later on after the introduction of the new organism in the environment. Moreover, the speed and the multitude of usable techniques dramatically multiplies and amplifies the risks of adverse effects. In any case, there are already so many different new techniques and there is the need of a case by case throughout assessment of whether or not any new produced organism is comparable to GMO.

The statement that gene editing can deliver a new green revolution is even more weak for promoting the alleged 'benefitsoutweighing-risks' of the technology.

First, it relies on the imaginary that the first green revolution brought only immense benefits, while there is awareness of its many shortcomings, ranging from the dangerous polluting chemicals dispersed in the environment, to the reduced soil fertility, and to the overuse of fossil fuels and its deleterious effects on climate change. Like the previous green revolution and the first wave of genetical innovations, gene editing is not going to deliver neither a world free from hunger, nor a more sustainable food system. Social scientists know, especially after the outstanding contribution of Amarthya Sen, that hunger does not depend on scarce food production but on poverty, wars and social discriminations that hinder the access to food. Even the demographic growth, which is presented as a "natural" occurring event, is simply the product of poverty and gender discrimination, which means that gender equality and social justice are the only means to fight hunger. With respect to the benefits to the environment magnified by proponents of gene editing, they are likely very limited, since most featured applications are not meant to induce resistance to biotic and abiotic stress but to increase the commercial value of crops in terms of higher variety and better adaptability to the increasingly industrialized food marketing channel. Among the 101 applications reported by Kawall et al. [4] only 21 refer to biotic and abiotic tolerance, with 66 applications referring to increased agronomic value and altered composition and 14 to herbicide tolerance and industrial utilization. Anyway, even in the case that most featured application would relate to abiotic stress, this would always give scarce contribution to sustainability because like all the adaptation policies they would 
offer a very limited solution to the climate change problem, which needs instead strong mitigation interventions.

Finally, the statement that gene editing can democratize agricultural biotechnologies is based on the evidence that its development seems to be driven by a more diverse group of developers and led mostly by small and medium enterprises (SMEs) and public research institutions; moreover, the CRISPR system is also praised for being cheap and easily accessible [19]. Unfortunately, on closer examination, the statement proves not to be accurate, as explained, among others, by a recent work [20] that highlights at least three concerns surrounding the alleged 'CRISPR democracy'. A first concern is the lack of authentic epistemic access, which means that people directly affected by the technologies, such as farmers, need not only to have access to the basic knowledge on the technology and to the open databases of genetic resources, but they need to be skilled in the language of genomic and have access to information technologies infrastructures that allow them to compute and use the available data. A second critical concern is the access to material and knowledge of practical utility, that to say that farmers do not need to have access to the tools of CRISPR technology, but to the real products (crops and seeds) stemming from the technology, which are usually covered by intellectual property rights owned by product developers. As early in 2016, Dow and DuPont already appeared to be in control of most of the technology's agricultural and food applications [21], joined in the following years by ChemChina and its newly acquired Syngenta [22]. The third concern refers to the flipside of the access problem. If CRISPR were to become more widely accessible, overcoming epistemic and resource boundaries, there would be risks of misuse and lack of risk management and control. Especially in the absence of socially agreed-upon regulation and governance, which would absolve industry from responsibility with "the democratization meme turned in a socialization of risk meme" [19].

\section{Organic farming and gene editing: the way forward}

The organic sector is striving to keep its material and ideal roots, while adjusting to a rapidly changing economic and sociotechnological landscape. From the very beginning, organic farming, beyond being an economic sector, has been a social movement aimed at building a true sustainable food system, where the three dimensions of sustainability (environmental, economic and social dimension) are given equal status and priority. In particular, the social dimension, the one that is constantly dismissed by the conventional agriculture and the agribusiness, has been always at the center of debates and decisional processes which by time have built, both at formal at informal level, the current institutional frame of the organic sector. The four mentioned principles of organic farming (Health, Ecology, Fairness, and Care) and the Via Campesina's [23,24] 'Seven Principles to Achieve Food Sovereignty' (1. Food as a basic human right; 2. agrarian reform, for giving marginal farmers and women ownership and control of the land they work; 3. protecting natural resources and assuring the right to conserve biodiversity free of restrictive intellectual property rights; 4. a fairer food trade; 5 . ending the globalization of hunger; 6 . social peace; 7. democratic control, encompassing gender equality) are shaping the attitudes within the movement also in the case of gene editing.

With respect to the new gene editing technologies, so far, a cautious precautionary principle has been embraced which has led the organic sector to refuse gene editing on the base of the two following arguments:

1. The technology does still not prove to be beneficial to society and be able to promote sustainable development.

2. There are too many areas of incertitude with respect to its possible adverse effects at environmental and social justice level [25].

Table 1: Featured gene-editing applications (in brackets the number of applications) assessed towards criteria for technological assessment.

\begin{tabular}{|c|c|c|c|c|c|}
\hline \multirow{2}{*}{$\begin{array}{l}\text { Featured Gene-Editing Applications (in Brackets the Num- } \\
\text { ber of Applications) } \\
\begin{array}{c}\text { Featured gene-editing Applications (adapted from Kawall et } \\
\text { al. [4]) }\end{array}\end{array}$} & \multicolumn{5}{|c|}{ Criteria for Technological Assessment } \\
\hline & $\begin{array}{l}\text { Consistency with } \\
\text { IFOAM principles }\end{array}$ & $\begin{array}{l}\text { Consistency with } \\
\text { Food Sovr. principles }\end{array}$ & $\begin{array}{c}\text { Safety } \\
\text { concerns }\end{array}$ & $\begin{array}{l}\text { Non-safety } \\
\text { concerns }\end{array}$ & Social utility \\
\hline $\begin{array}{l}\text { Increased agronomic value (38): increased yield, improved } \\
\text { storage, altered flowering time/maturation }\end{array}$ & poor & poor & unknown & very likely & poor \\
\hline $\begin{array}{l}\text { Altered composition (28): reduced lignin content, altered } \\
\text { fatty acid composition, increased nutritional value }\end{array}$ & very poor & very poor & unknown & very likely & poor \\
\hline $\begin{array}{l}\text { Biotic stress tolerance (16) fungal resistance, bacterial } \\
\text { resistance }\end{array}$ & possible & possible & unknown & likely & possible \\
\hline $\begin{array}{l}\text { Herbicide tolerance (8): tolerance to glyphosate, tolerance to } \\
\text { imidazolinone sulfonylurea (ALS inhibitors) }\end{array}$ & very poor & very poor & unknown & very likely & very poor \\
\hline Abiotic stress tolerance (5): drought tolerance, salt tolerance & possible, but weak & possible, but weak & unknown & likely & $\begin{array}{l}\text { possible, } \\
\text { but weak }\end{array}$ \\
\hline $\begin{array}{l}\text { Industrial utilisation (6): improved starch quality, altered oil } \\
\text { composition }\end{array}$ & very poor & very poor & unknown & very likely & poor \\
\hline
\end{tabular}


Table 1 reassumes some of the stances that the organic sector is taking in its assessment effort of gene editing technologies. The organic sector is also reacting to the pressure by the many proponents of gene editing, present also in organizations and fora traditionally sympathizer of organic farming, trying to erect clear and solid boundaries for reaffirming not only its general principles but also the technological peculiarity and value of organic agronomical practices [15]. In a very rigorous way, it refers to the richness and usefulness of agricultural technologies used by organic farming, with their proven benefits in the face of the promised benefits, but for now far from being proven, of new bioengineering technologies.

Notwithstanding the clear position taken by IFOAM, it is very likely that the debate on gene editing will reignite soon, with renovated stances and emerging contradictions. There are at least three forces pushing towards a revision of the current position: the force of the current technological paradigm; the internal diversity of the organic sector and the latent contradiction within the sector stemming from the market vs social/community orientation; the regulatory frameworks and policy intervention established by governments and international bodies.

Gene editing technologies are fully embedded in the current technological paradigm, i.e., the Information and Communication Technology (ICT) paradigm, which is shaping the current agribusiness-led innovation trajectory of the food system. Alternative to such trajectory there is the agroecology innovation trajectory [26], where organic agriculture may find its own place and function. In order for the agroecology innovation trajectory to help building a true sustainable and resilient food system the definition of breeding techniques which assure innovative agronomic solutions, free accessibility and preservation on natura biodiversity is of utmost importance. Because of the many economic interests and its integration in the current ICT technology paradigm gene editing may disrupt in a short time enormous baggage of knowledge and genetic resources, forcing farmers all over the world to depend on a few private agricultural input companies. The effort that the organic sector is making in offering solid and safe alternatives to the "magic" of gene editing is an important contribution for building new resilient and fair food systems. Nevertheless, such an effort might not be successfully, since a technological paradigm tends to influence and incorporate all activities through a cultural (the paradigm is established precisely because it becomes part of the dominant culture) and material change, creating new technological standards and network economies that make it difficult for alternative technologies to survive.

The second obstacle for opposing gene technologies stems from the possible constraints of the competitive environment faced by organic farmers. Since the late 1970s the organic sector has evolved with a strong market orientation [27]. Local production systems, with forms of community exchange or self-consumption are currently extremely rare. On the contrary, organic farms are generally structurally and economically quite strong, often export- oriented and well-integrated with the modern food distribution. As consequence, at any moment, incentives for using gene editing could come from the distributive sector, from consumers' changing preferences or as a response to the strategies implemented by their competitors.

Finally, whatever the principles endorsed by the sector, its real policies and actions will depend on the general regulatory framework and public policies offered by governments. In its effort to maintain an alternative food model, the organic sector needs support by scientists and public authorities. In order to leave room for a diversified food and agriculture technological landscape, more useful to cope with risks and uncertainties raising from climate change and environment deterioration, the following interventions should be implemented [26].

1. Strengthening competition policy.

2. Renovating the international system of patent laws, that should be revised and adapted to the new technologies and their transnational diffusion and control.

3. Strengthening environmental regulations.

4. Technology risk analysis, considering safety and non-safety risks and the democratization of risk control, which in the first instance requires the knowledge and awareness of citizens.

5. Funding public research; substantial investments in public research are essential to curb the privatization of knowledge that is the basis of many social risks related to technological change.

6. Recognizing organic farming and agroecology as effective and science-based agricultural technologies, and therefore give them the same financial support in terms of research programs, education and agricultural extension.

As long as these interventions will be not firmly implemented, the possibility for the organic sector to oppose the new gene technologies will be very tiny.

\section{References}

1. Doudna JA, Charpentier E (2014) The new frontier of genome engineering with CRISPR-Cas9. Science 346(6213): 1258096.

2. Zhang D, Hussain A, Manghwar H, Xie K, Xie S, et al. (2020) Genome editing with the CRISPR-Cas system: an art, ethics and global regulatory perspective. Plant Biotechnol J 18(8): 1651-1669.

3. Ricroch A (2019) Global developments of genome editing in agriculture. Transgenic Res 28 (Suppl 2): 45-52.

4. Kawall K, Cotter J, Then C (2020) Broadening the GMO risk assessment in the EU for genome editing technologies in agriculture. Environ Sci Eur 32: 106 .

5. Jin S, Zong Y, Gao Q, Zhu Z, Wang Y, et al. (2019) Cytosine, but not adenine, base editors induce genome wide off-target mutations in rice. Science 364(6437): 292-295.

6. Jie Liu, Alisdair R. Fernie, Jianbing Yan (2021) Crop breeding-From experience-based selection to precision design. Journal of Plant Physiology 256: 153313. 
7. Gaëtan Burgio, Lydia Teboul (2020) Anticipating and identifying collateral damage in genome editing. Trends in Genetics 36(12): 905914.

8. Waltz E (2018) With a free pass, CRISPR-edited plants reach market in record time. Nat Biotechnol 36(1): 6-7.

9. European Court of Justice (ECJ) (2018) Press release No 111/18, Luxembourg.

10. Myskja BK, Myhr AI (2020) Non-safety assessments of genome-edited organisms: Should they be included in regulation? Sci Eng Ethics 26(5): 2601-2627.

11. Scrinis G, Lyons K (2007) The emerging nano-corporate paradigm: nanotechnology and the transformation of nature, food and agrifood systems. Int J Sociol Food Agric 15(2): 22-44.

12. McMichael P (2009) A food regime analysis of the 'world food crisis' Agric Hum Values 26: 281-295.

13. Sodano V (2018) Food nanotechnologies and policy challenges. Environ Chem Lett 16: 5-10.

14. IFOAM (2016) Position on genetic engineering and genetically modified organisms.

15. IFOAM-Organics International (2017) Position paper compatibility of breeding techniques in organic systems.

16. Wickson F, Binimelis R, Herrero A (2016) Should organic agriculture maintain its opposition to GM? New techniques writing the same old story. Sustainability 8(11): 1105.

17. Ryffel GU (2017) I have a dream: Organic movements include gene manipulation to improve sustainable farming. Sustainability 9(3): 392.
18. Bain C, Lindberg S, Selfa T (2020) Emerging sociotechnical imaginaries for gene edited crops for foods in the United States: implications for governance. Agric Hum Values 37: 265-279.

19. Whelan AI, Gutti P, Lema MA (2020) Gene editing regulation and innovation economics. Front Bioeng Biotechnol 8: 303.

20. Montenegro de Wit M (2020) Democratizing CRISPR? Stories, practices, and politics of science and governance on the agricultural gene editing frontier. Elem Sci Anth 8: 9.

21. Egelie KJ, Graff GD, Strand SP, Johansen B (2016) The emerging patent landscape of CRISPR-Cas gene editing technology. Nature Biotechnology 34(10): 1025-1031.

22. Cohen J (2019) China's CRISPR revolution. Science 365(6452): 420-421.

23. Caro P (2011) Food sovereignty: exploring debates on development alternatives and women's rights. Awid, Toronto, Canada.

24. Borras SM (2008) La vía campesina and its global campaign for agrarian reform. Journal of Agrarian Change 8(2-3): 258-289.

25. Nawaz S (2020) Tensions at the boundary: Rearticulating 'organic' plant breeding in the age of gene editing. Elem Sci Anth 8: 34.

26. Sodano V (2019) Innovation trajectories and sustainability in the food system. Sustainability 11(5): 1271.

27. Arbenz M, Gould D, Stopes C (2017) ORGANIC 3.0-the vision of the global organic movement and the need for scientific support. Org Agric 7: 199207.

For possible submissions Click below: 